\title{
Lymphocyte Cell Biology
}

National Cancer Institute

\section{Source}

National Cancer Institute. Lymphocyte Cell Biology. NCI Thesaurus. Code C18865.

The structure and biological function of lymphocytes in the body. 